\title{
Tiliroside, the major component of Agrimonia pilosa Ledeb ethanol extract, inhibits MAPK/JNK/p38-mediated inflammation in lipopolysaccharide-activated RAW 264.7 macrophages
}

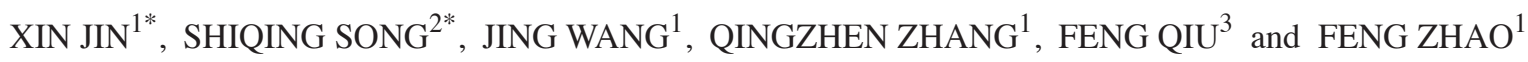 \\ ${ }^{1}$ Key Laboratory of Molecular Pharmacology and Drug Evaluation, Ministry of Education of China, \\ School of Pharmacy, Yantai University, Yantai, Shandong 264005; ${ }^{2}$ Department of Rehabilitation Medicine, \\ Yantai Yu-Huang-Ding Hospital, Yantai, Shandong 264000; ${ }^{3}$ Tianjin State Key Laboratory of Modern Chinese Medicine, \\ School of Chinese Materia Medica, Tianjin University of Traditional Chinese Medicine, Tianjin 300193, P.R. China
}

Received May 14, 2015; Accepted February 11, 2016

DOI: 10.3892/etm.2016.3305

\begin{abstract}
In the present study, the in vivo anti-inflammatory activity of Agrimonia pilosa Ledeb (AP) ethanol extract was confirmed in experimental animal models, including xylene-induced ear edema in mice and carrageenan-induced paw edema in rats. Tiliroside, the major component of AP extract, was isolated and purified by high-performance liquid chromatography. The anti-inflammatory mechanism of tiliroside was then examined using lipopolysaccharide (LPS)-activated RAW 264.7 macrophage cells. An MTT assay was used to determine cytotoxicity and a Griess assay was used to determine nitric oxide (NO) production. Concentration levels of tumor necrosis factor- $\alpha$ (TNF- $\alpha$ ) and interleukin-6 (IL-6) were determined by enzyme-linked immunosorbent assay. Protein expression levels of inducible nitric oxide synthase (iNOS), cyclooxygenase-2 (COX-2), phosphorylated (p)-extracellular signal-regulated kinase (ERK) $1 / 2$, p-c-Jun N-terminal kinases (JNK), p-p38 and inhibitor of $\kappa \mathrm{B}-\alpha$ were detected by western blot analysis. AP ethanol extract was revealed to inhibit xylene-induced ear edema in mice and carrageenan-induced paw edema in rats. Tiliroside
\end{abstract}

Correspondence to: Dr Feng Zhao, Key Laboratory of Molecular Pharmacology and Drug Evaluation, Ministry of Education of China, School of Pharmacy, Yantai University, 30 Qingquan Road, Laishan, Yantai, Shandong 264005, P.R. China

E-mail: ytuzhaofeng@163.com

Professor Feng Qiu, Tianjin State Key Laboratory of Modern Chinese Medicine, School of Chinese Materia Medica, Tianjin University of Traditional Chinese Medicine, 88 Yuquan Road, Tianjin 300193, P.R. China

E-mail: fengqiu20070118@163.com

*Contributed equally

Key words: Agrimonia pilosa Ledeb, tiliroside, inducible nitric oxide synthase, cyclooxygenase-2, mitogen-activated protein kinase significantly suppressed the overproduction of $\mathrm{NO}(\mathrm{P}<0.01)$, but revealed no notable inhibition of the release of TNF- $\alpha$ and IL-6. In addition, tiliroside significantly downregulated the elevated expression levels of iNOS and COX-2 induced by LPS $(\mathrm{P}<0.01)$. The phosphorylation of JNK and $\mathrm{p} 38$ proteins were also significantly inhibited $(\mathrm{P}<0.01)$, however, tiliroside exhibited no obvious inhibition on the phosphorylation of ERK $1 / 2$ and the degradation of I $\mathrm{KB}-\alpha$ protein. In conclusion, the anti-inflammatory molecular mechanism of tiliroside may involve the downregulation of iNOS and COX-2 protein expression levels, and the inactivation of mitogen-activated protein kinase (MAPK)/JNK, in addition to the MAPK/p38 signaling pathway.

\section{Introduction}

Agrimonia pilosa Ledeb (Rosaceae; AP) is a perennial herbaceous flowering plant distributed in the temperate regions of the Northern hemisphere, including Asia. As a traditional medicinal plant, it has been used for the treatment of abdominal pain, sore throat, headaches, bloody discharge, parasitic infections and eczema (1). Pharmacological research has revealed that AP extracts possess diverse pharmacological properties, including antinociceptive (1), antiplatelet (2) and antihemostatic effects (3), in addition to antioxidant (4), antiviral (5), antitumor (6), anti-inflammatory, anti-allergic $(7,8)$, anti-microbial (9) and anti-hyperglycemic (10) activity, amongst others. Tiliroside, a glycosidic flavonoid (Fig. 1), is the major component of AP extracts. Tiliroside has been reported to exhibit the following: Anti-diabetic properties by enhancing glucose consumption by insulin-resistant HepG2 cells $(11,12)$; antihypertensive and vasorelaxant effects in resistance arteries (13); anti-hyperglycemic, anti-hyperlipidemic and antioxidant activities (14); as well as an inhibitory effect on important human liver cytochrome p450 enzymes (15). Tiliroside and two other flavonoids have been analyzed in vitro for their antioxidant properties and in vivo for their anti-inflammatory properties. In vivo, tiliroside significantly inhibited the mouse paw edema induced by phospholipase A and the mouse ear inflammation induced by 12 -O-tetradecano 
ylphorbol-13-acetate (16). However, the molecular mechanism of the anti-inflammatory action of tiliroside has yet to be elucidated. In the present study, the aforementioned molecular mechanism of tiliroside in LPS-activated macrophages was investigated.

\section{Materials and methods}

Reagents. RPMI-1640 medium and fetal bovine serum (FBS) were purchased from Invitrogen (Thermo Fisher Scientific, Inc., Waltham, MA, USA). Lipopolysaccharide (LPS; L2880), MTT, hydrocortisone (hydro; H4001), sodium carboxymethyl cellulose (CMC), p-xylene and carrageenan were purchased from Sigma-Aldrich (St. Louis, MO, USA). The BCA protein concentration assay kit was purchased from Yantai Science \& Biotechnology Co., Ltd. (Yantai, China) and dectancyl dexamethasone acetate was obtained from Cisen Pharmaceutical Co., Ltd. (Jining, China). Mouse anti-rabbit iNOS (inducible nitric oxide synthase) polyclonal antibody (160862; Cayman Chemical Company, Ann Arbor, MI, USA), mouse anti-rabbit COX-2 (cyclooxygenase-2) polyclonal antibody (160106; Cayman Chemical Company), goat anti-rabbit phosphorylated extracellular signal-regulated kinase (p-ERK 1/2) polyclonal antibody (AF1015; Affinity Biosciences, Zhenjiang, China), goat anti-rabbit phosphorylated c-Jun N-terminal kinase (p-JNK) polyclonal antibody (AF3318; Affinity Biosciences), goat anti-rabbit phosphorylated p38 (p-p38) polyclonal antibody (AF3455; Affinity Biosciences), goat anti-rabbit IкB- $\alpha$ polyclonal antibody (sc-371; Santa Cruz Biotechnology, Inc.), goat anti-rabbit $\beta$-actin polyclonal antibody (sc-1616; Santa Cruz Biotechnology, Inc.) and horseradish peroxidase (HRP)-conjugated goat anti-rabbit IgG (H+L) (S0001; Affinity Biosciences) were used at 1:1,000 dilution. A $50 \mathrm{mM}$ solution of tiliroside was prepared in $100 \%$ cell culture grade dimethyl sulfoxide (DMSO), stored as small aliquots at $-20^{\circ} \mathrm{C}$ and diluted to the required concentrations prior to use.

Plant material and preparation of ethanol extract. The dried herb of AP was purchased from Shenyang Dongbei Pharmacy Chainstore Co., Ltd. (Shenyang, China) and identified by Professor Qishi Sun of the School of Traditional Chinese Materia Medica, Shenyang Pharmaceutical University (Shenyang, China). A voucher specimen (no. 20061010) was deposited in the herbarium of the Department of Natural Products Chemistry, Shenyang Pharmaceutical University. AP herb $(10 \mathrm{~kg})$ was extracted with $70 \%$ ethanol under reflux $(2 \mathrm{~h}$, twice). The extracted solution was filtered through filter paper, and evaporated under reduced pressure at $0.098 \mathrm{KPa}$ (Yuhua Instrument Co., Ltd., Gongyi, China) to obtain the AP ethanol extract $(1 \mathrm{~kg})$.

Isolation and identification of tiliroside. The ethanol extract was resuspended in water, and then partitioned with the same volume of hexane, ethyl acetate and n-butanol to yield hexane, ethyl acetate and n-butanol fractions, respectively, in addition to an $\mathrm{H}_{2} \mathrm{O}$ fraction. The ethyl acetate extract (108 g) was subjected to silica gel column chromatography with a $\mathrm{CHCl}_{3}-\mathrm{MeOH}$ gradient solvent system (100:0 to 0:100) to obtain 9 fractions (termed APE1-APE9), which were separated according to thin layer chromatography analysis. Fraction

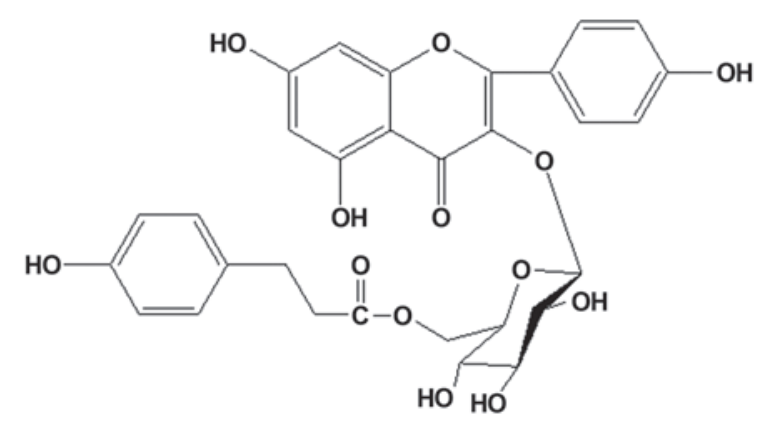

Figure 1. Chemical structure of tiliroside.

APE7 was crystallized from methanol to yield a yellow compound $(20 \mathrm{~g})$. The chemical structure of this compound was determined to be tiliroside by analysis of the spectroscopic data (Fig. 1). The purity was determined to be $99.2 \%$ by normalization of the peak areas in high-performance liquid chromatography (UV detector).

Experimental animals. Male KM mice (weight, 18-22 g; age, 5 weeks) and male Wistar rats weighing 160-200 g were purchased from Beijing Hua Fu Kang Bioscience Co., Ltd. (Beijing, China). All experimental procedures conducted in the present study were performed in accordance with the guidelines for the care and use of laboratory animals of Yantai University (Yantai, China), and were approved by the Ethics Committee of Yantai University. All animals were randomly divided into groups and housed in standard plastic cages at room temperature $\left(22 \pm 2^{\circ} \mathrm{C}\right)$ with a 12 -h light-dark cycle. The animals had free access to food and water.

Xylene-induced ear edema in mice. Mice $(\mathrm{n}=48)$ were randomly divided into six groups $(\mathrm{n}=8)$, as follows: Vehicle control [sodium CMC]; $250 \mathrm{mg} / \mathrm{kg}, 500 \mathrm{mg} / \mathrm{kg}, 1,000 \mathrm{mg} / \mathrm{kg}$ and $2,000 \mathrm{mg} / \mathrm{kg}$ AP ethanol extract; and $5 \mathrm{mg} / \mathrm{kg}$ dexamethasone. AP ethanol extract and dexamethasone were administered by gastric perfusion once daily for 3 days. The vehicle control group was administered an equivalent volume of $2.5 \%$ sodium CMC solution. Xylene $(10 \mu \mathrm{l})$ was added dropwise onto the anterior and posterior surfaces of the right ear $4 \mathrm{~h}$ after gastric perfusion on the third day, while the left ear was used as a control. Mice were sacrificed by cervical dislocation $2 \mathrm{~h}$ after xylene application. Subsequently, both ears of the mice were removed, and ear disks measuring $9 \mathrm{~mm}$ in diameter were punched using a cork borer (YLS-25A; Jinan Yiyan Biotechnology, Jinan, China) and weighed. The extent of edema was evaluated by the weight difference between the right and the left ear disks of the same animal, according to the following formula:

$$
\text { Percentage increase }(\%)=\frac{\mathrm{w}_{\text {treated }}-\mathrm{w}_{\text {negative control }}}{\mathrm{w}_{\text {negative control }} \times 100}
$$

where $\mathrm{w}$ indicates weight of the ear.

Carrageenan-induced paw edema in rats. Wistar rats $(\mathrm{n}=48)$ were randomly divided into six groups $(n=8)$ as follows: 
Vehicle control; $250 \mathrm{mg} / \mathrm{kg}, 500 \mathrm{mg} / \mathrm{kg}, 1,000 \mathrm{mg} / \mathrm{kg}$ and $2,000 \mathrm{mg} / \mathrm{kg}$ AP ethanol extract; and $5 \mathrm{mg} / \mathrm{kg}$ dexamethasone. AP ethanol extract and dexamethasone were administered by gastric perfusion once daily for 3 days. The vehicle control group was administered with an equivalent volume of $2.5 \%$ sodium CMC solution. Carrageenan $(0.1 \mathrm{ml}, 1 \% \mathrm{w} / \mathrm{v})$ was injected into the right-hind paw (sub-plantar) $2 \mathrm{~h}$ after the final administration. Paw volume was measured prior to the irritant injection and at selected intervals $(0,1,2,4 \mathrm{~h})$ thereafter with a hydro-plethysmometer (Shandong Academy of Medical Sciences, Jinan, China). Results are expressed according to the increase in paw volume $(\mathrm{ml})$ calculated by subtracting the basal volume.

Cell culture of RAW 264.7 cells. RAW 264.7 cells (ATCC TIB-71; American Type Culture Collection, Manassas, VA, USA) were maintained in RPMI-1640 medium supplemented with $10 \%$ heat-inactivated $\mathrm{FBS}$ at $37^{\circ} \mathrm{C}$ in a humidified incubator. The medium was routinely changed every 2 days. RAW 264.7 cells were passaged using $0.25 \%$ (w/v) trypsin (Yantai Science and Biotechnology, Co., Ltd.) until they reached $80 \%$ confluence.

MTT assay to determine cell viability. To determine the effect of tiliroside on cell viability, RAW 264.7 cells were cultured in 96-well plates at a density of $2 \times 10^{5}$ cells/well. Following a 24-h incubation period, the cells were then treated with serially diluted tiliroside at concentrations of $1.5625-100 \mu \mathrm{M}$. The mitochondrial-dependent reduction of MTT to formazan was used to measure cell respiration as an indicator of cell viability (17). Briefly, following tiliroside treatment, an MTT solution was added at a final concentration of $200 \mu \mathrm{g} / \mathrm{ml}$ and the cells were incubated for another $4 \mathrm{~h}$. Following removal of the supernatant, $150 \mu 1 \mathrm{DMSO}$ was added to dissolve the formazan. The absorbance was measured by a microplate reader (Biotek Synergy HT; BioTek Instruments, Inc., Winooski, VT, USA) at $570 \mathrm{~nm}$, using $630 \mathrm{~nm}$ as a reference wavelength. The untreated cells were considered to be $100 \%$ viable. Results are expressed as the percentage of viable cells compared with untreated cells.

Nitric oxide (NO) analysis. NO levels were determined by measuring the quantity of nitrite in the cell culture supernatant using Griess reagent (Yantai Science \& Biotechnology, Co., Ltd.) (18). RAW 264.7 cells were cultured in 96-well plates at a density of $2 \times 10^{5}$ cells/well. Following this, the cells were treated with LPS $(1 \mu \mathrm{g} / \mathrm{ml})$ with or without the addition of tiliroside $(12.5,25,50$ and $100 \mu \mathrm{M})$ and then incubated for $24 \mathrm{~h}$. Cell culture supernatant $(100 \mu \mathrm{l})$ was mixed with $100 \mu \mathrm{l}$ Griess reagent and the absorbance was measured at $540 \mathrm{~nm}$. The nitrite concentrations were calculated using a standard calibration curve prepared from different concentrations of sodium nitrite.

Determination of TNF- $\alpha$ and IL-6. RAW 264.7 cells were cultured in $96-$ well plates at a density of $2 \times 10^{5}$ cells/well. The cells were treated with LPS $(1 \mu \mathrm{g} / \mathrm{ml})$ with or without tiliroside $(12.5,25,50$ and $100 \mu \mathrm{M})$ and then incubated for $6 \mathrm{~h}$. Cell culture supernatant $(100 \mu \mathrm{l})$ was removed to determine the levels of TNF- $\alpha$ or IL- 6 by using respective mouse TNF- $\alpha$ (SEM024) and mouse IL-6 (SEM008) enzyme-linked immunosorbent assay (ELISA) kits (Yantai Science \& Biotechnology, Co., Ltd.), as previously described (19).

Protein extraction. For the detection of iNOS and COX-2 expression, RAW 264.7 cells were harvested following the indicated treatments for $24 \mathrm{~h}$. For detection of p-ERK, p-JNK and p-p38, RAW 264.7 cells were harvested after the indicated treatments for $45 \mathrm{~min}$. For detection of IкB- $\alpha$ degradation, RAW 264.7 cells were harvested after indicated treatments for $15 \mathrm{~min}$. Cells were washed with cold phosphate-buffered saline and lysed in a cold lysis buffer (Yantai Science \& Biotechnology, Co., Ltd.) to obtain the total protein, as previously described (20). The total protein concentrations were determined using a BCA protein concentration assay kit.

Western blot analysis. Equal quantities (30 $\mu \mathrm{g})$ of the respective proteins were boiled with SDS-PAGE loading buffer, subjected to $10 \%$ SDS-PAGE and electrophoretically transferred onto nitrocellulose membranes (Pall Corporation, Port Washington, NY, USA). The membranes were blocked with 5\% non-fat dried milk in Tris-buffered saline with Tween (TBS-T; Yantai Science \& Biotechnology, Co., Ltd.) at room temperature for $4 \mathrm{~h}$. After washing, the membranes were incubated in the respective primary antibody solution (iNOS, COX-2, p-ERK 1/2, p-JNK, p-p38, IкB- $\alpha$ or $\beta$-actin) overnight at $4^{\circ} \mathrm{C}$. The membranes were washed with TBS-T and incubated with the relevant HRP-conjugated secondary antibody solution at room temperature for $1 \mathrm{~h}$. Subsequent to washing the membranes, the bands were detected by enhanced chemiluminescence (Beyotime Institute of Biotechnology, Shanghai, China) and exposed to X-ray films (Eastman Kodak Company, Rochester, NY, USA). Developed images were collected and the bands were quantitated by densitometric analysis using the DigDoc100 program (Gel-pro analyzer 3.2; AlphaEaseFC software; Genetic Technologies, Inc., Miami, FL, USA). Expression data for iNOS, COX-2, p-ERK, p-JNK, p-p38 and IкB- $\alpha$ were normalized with respect to $\beta$-actin expression levels.

Statistical analysis. All results are expressed as means \pm standard deviation. Statistical comparisons were conducted using Origin 7.5 software (OriginLab Corporation, Northampton, MA, USA). $\mathrm{P}<0.05$ was considered to indicate a statistically significant difference.

\section{Results}

Effect of AP ethanol extract on xylene-induced ear edema in mice. As displayed in Fig. 2, xylene-induced ear edema in mice was significantly decreased by oral administration of $2,000 \mathrm{mg} / \mathrm{kg}$ AP ethanol extract $(2.66 \pm 0.25 \mathrm{mg})$ compared with the vehicle control group $(\mathrm{P}<0.01 ; 6.08 \pm 0.37 \mathrm{mg})$. However, lower doses of AP ethanol extract $(1,000$, 500 and $250 \mathrm{mg} / \mathrm{kg}$ ) did not exhibit significant inhibition on xylene-induced ear edema in mice. The high dose of AP ethanol extract $(2,000 \mathrm{mg} / \mathrm{kg})$ produced significant inhibition that was approximately equal to the positive control group (5 $\mathrm{mg} / \mathrm{kg}$ dexamethasone).

Effect of AP ethanol extract on carrageenan-induced paw edema in rats. As revealed in Fig. 3, treatment with AP ethanol 


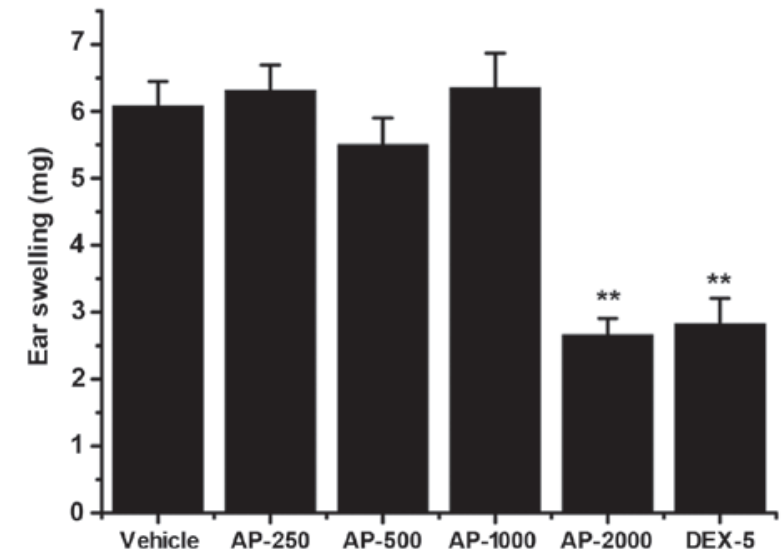

Figure 2. Effect of AP ethanol extract on xylene-induced ear edema in mice. Mice (n=8/group) were treated with $250,500,1,000$ and 2,000 mg/kg AP ethanol extract or $5 \mathrm{mg} / \mathrm{kg}$ DEX-5. Both ears were harvested after $10 \mu 1$ xylene was applied to the right ear. Data are presented as the mean \pm standard deviation. ${ }^{* *} \mathrm{P}<0.01$ vs. vehicle control group. AP, Agrimonia pilosa; DEX-5, dexamethasine-5.

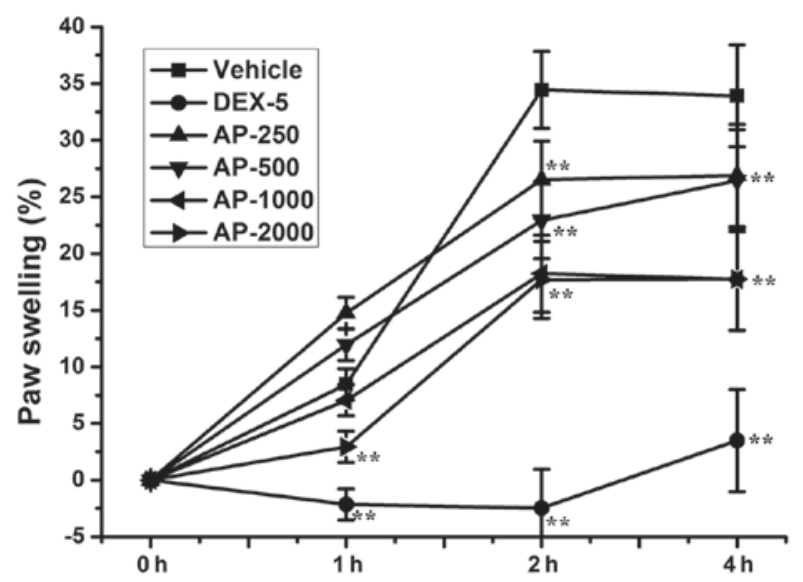

Figure 3. Effect of AP ethanol extract on carrageenan-induced paw edema in rats. Rats (n=8/group) were treated with $250,500,1,000$ and $2,000 \mathrm{mg} / \mathrm{kg} \mathrm{AP}$ ethanol extract or $5 \mathrm{mg} / \mathrm{kg} \mathrm{DEX}-5$. The paw volume was measured at selected intervals after $0.1 \mathrm{ml}$ carrageenan was injected into the right-hind paw. Data are presented as the mean \pm standard deviation. ${ }^{* *} \mathrm{P}<0.01$ vs. vehicle control group. AP, Agrimonia pilosa; DEX-5, dexamethasone-5.

extract significantly inhibited the development of paw edema at $2(\mathrm{P}<0.01)$ and $4 \mathrm{~h}(\mathrm{P}<0.01)$ after carrageenan injection compared with the vehicle group. Dexamethasone significantly reduced carrageenan-induced paw edema at $1(\mathrm{P}<0.01), 2(\mathrm{P}<0.01)$ and $4 \mathrm{~h}(\mathrm{P}<0.01)$ after carrageenan injection compared with the vehicle group, and almost completely prevented paw swelling

Tiliroside does not exhibit cytotoxicity against RAW 264.7 macrophages. RAW 264.7 cells were treated with between 1.5625 and $100 \mu \mathrm{M}$ of tiliroside for $24 \mathrm{~h}$. An MTT assay was used to assess cell viability, as described in the Materials and methods section. The results indicated that tiliroside does not display significant cytotoxicity to RAW 264.7 cells at this dose range (data not shown).

Effect of tiliroside on NO production. RAW 264.7 cells were treated with LPS $(1 \mu \mathrm{g} / \mathrm{ml})$ with or without the indicated

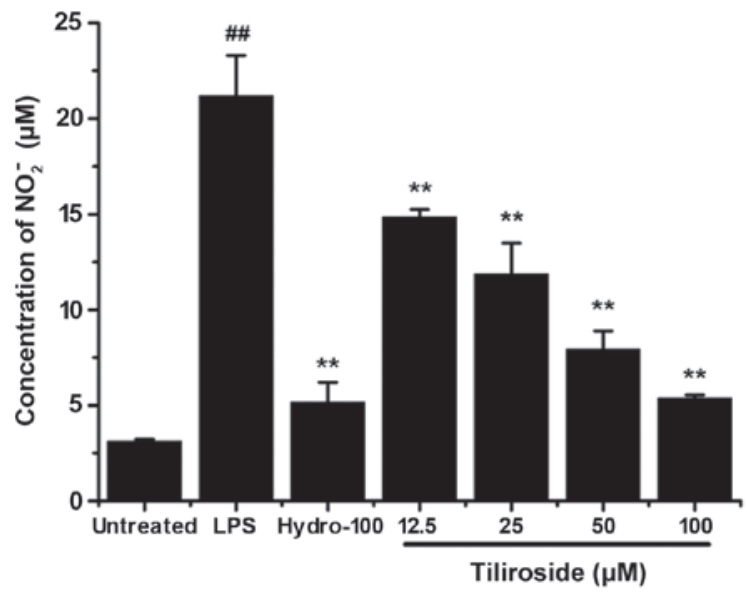

Figure 4. Inhibitory effect of tiliroside on $\mathrm{NO}_{2}^{-}$production induced by LPS. RAW 264.7 cells were treated with $1 \mu \mathrm{g} / \mathrm{ml}$ LPS with or without tiliroside $(12.5,25,50$ and $100 \mu \mathrm{M})$ or hydrocortisone $(100 \mu \mathrm{M})$ for $24 \mathrm{~h}$. $\mathrm{NO}_{2}{ }^{-}$concentrations were measured in triplicate. Data are presented as the mean \pm standard deviation of three separate experiments. ${ }^{* *} \mathrm{P}<0.01 \mathrm{vs}$. LPS treatment group; ${ }^{\# \#} \mathrm{P}<0.01$ vs. untreated group. LPS, lipopolysaccharide; Hydro, hydrocortisone.

concentrations of tiliroside $(12.5,25,50$ and $100 \mu \mathrm{M})$ for $24 \mathrm{~h}$. The concentration of nitrite in the supernatant was determined as the NO production level. As displayed in Fig. 4, tiliroside significantly inhibited LPS-induced NO overproduction in a dose-dependent manner $(\mathrm{P}<0.01)$.

Effect of tiliroside on TNF- $\alpha$ and IL-6 release. RAW 264.7 cells were treated with LPS $(1 \mu \mathrm{g} / \mathrm{ml})$ with or without the indicated concentrations of tiliroside $(12.5,25,50$ and $100 \mu \mathrm{M})$ for $6 \mathrm{~h}$. The concentrations of TNF- $\alpha$ and IL-6 in the supernatant were determined using the respective ELISA kits. As displayed in Fig. 5A and B, tiliroside exhibited no inhibitory effect on the release of TNF- $\alpha$ and only a weak inhibitory effect on the release of IL-6, respectively.

Tiliroside significantly downregulates the protein expression levels of iNOS and COX-2 induced by LPS. iNOS and COX-2 expression levels were examined by western blot analysis (Fig. 6A). The density of bands corresponding to iNOS and COX-2 protein expression levels were normalized to $\beta$-actin, and are displayed in Fig. 6B and C, respectively. As revealed in Fig. 6, treatment with LPS significantly induced high expression of iNOS and COX-2 proteins $(\mathrm{P}<0.01)$. Tiliroside significantly inhibited the expression levels of iNOS protein in a dose-dependent manner $(\mathrm{P}<0.01)$, which suggests that the decrease in NO production was due to the suppression of iNOS protein. Furthermore, tiliroside significantly downregulated the expression of COX-2 in a dose-dependent manner $(\mathrm{P}<0.01)$.

Effectoftilirosideonthephosphorylationofmitogen-activated protein kinase (MAPK) ERK1/2, JNK and p38 proteins. It has previously been demonstrated that the MAPK signaling pathways are associated with LPS-induced inflammatory reactions. Furthermore, LPS-mediated activation of the MAPK signaling pathway predominately involves the phosphorylation of ERK1/2, JNK and p38 proteins (21). As displayed in 

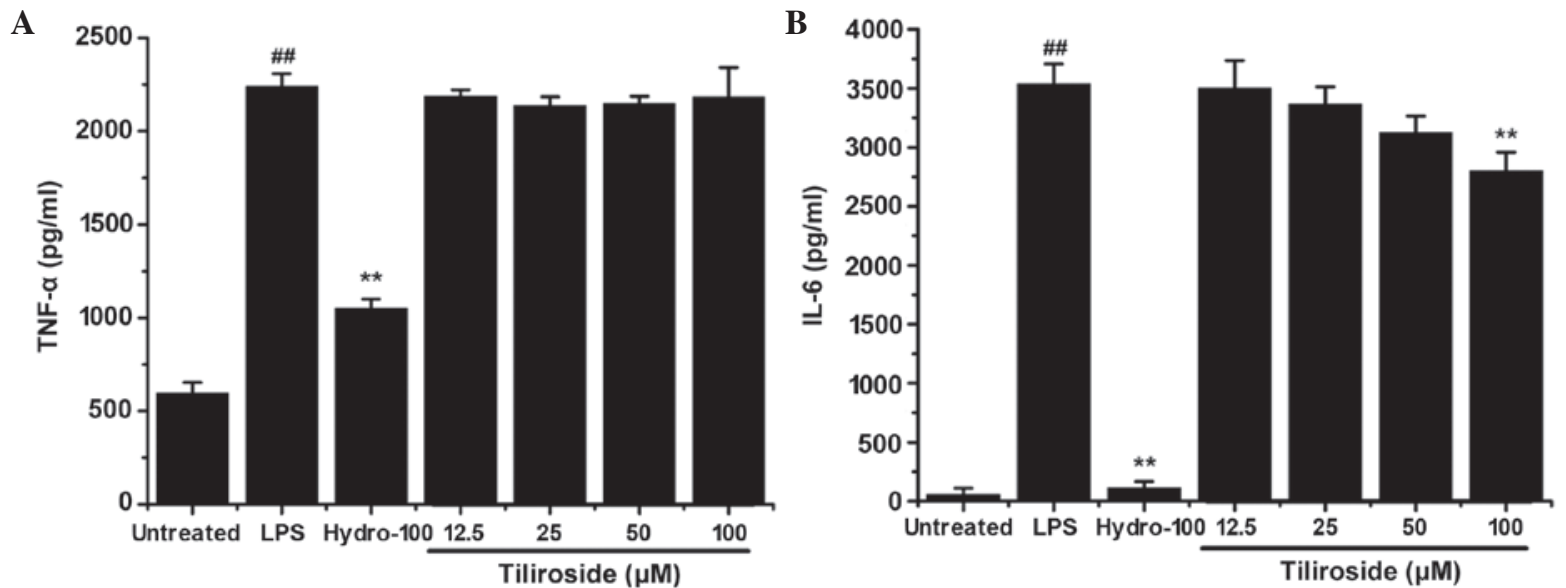

Figure 5. Effect of tiliroside on the release of (A) TNF- $\alpha$ and (B) IL-6. RAW 264.7 cells were treated with $1 \mu \mathrm{g} / \mathrm{ml}$ LPS with or without tiliroside (12.5, 25, 50 and $100 \mu \mathrm{M})$ or hydrocortisone $(100 \mu \mathrm{M})$ for $6 \mathrm{~h}$. The supernatant was analyzed to determine the expression levels of TNF- $\alpha$ and IL- 6 . Data are presented as the mean \pm standard deviation of three separate experiments. ${ }^{* *} \mathrm{P}<0.01$ vs. LPS treatment group; ${ }^{\# \#} \mathrm{P}<0.01$ vs. untreated group. LPS, lipopolysaccharide; Hydro, hydrocortisone; IL-6, interleukin-6. TNF- $\alpha$, tumor necrosis factor- $\alpha$.

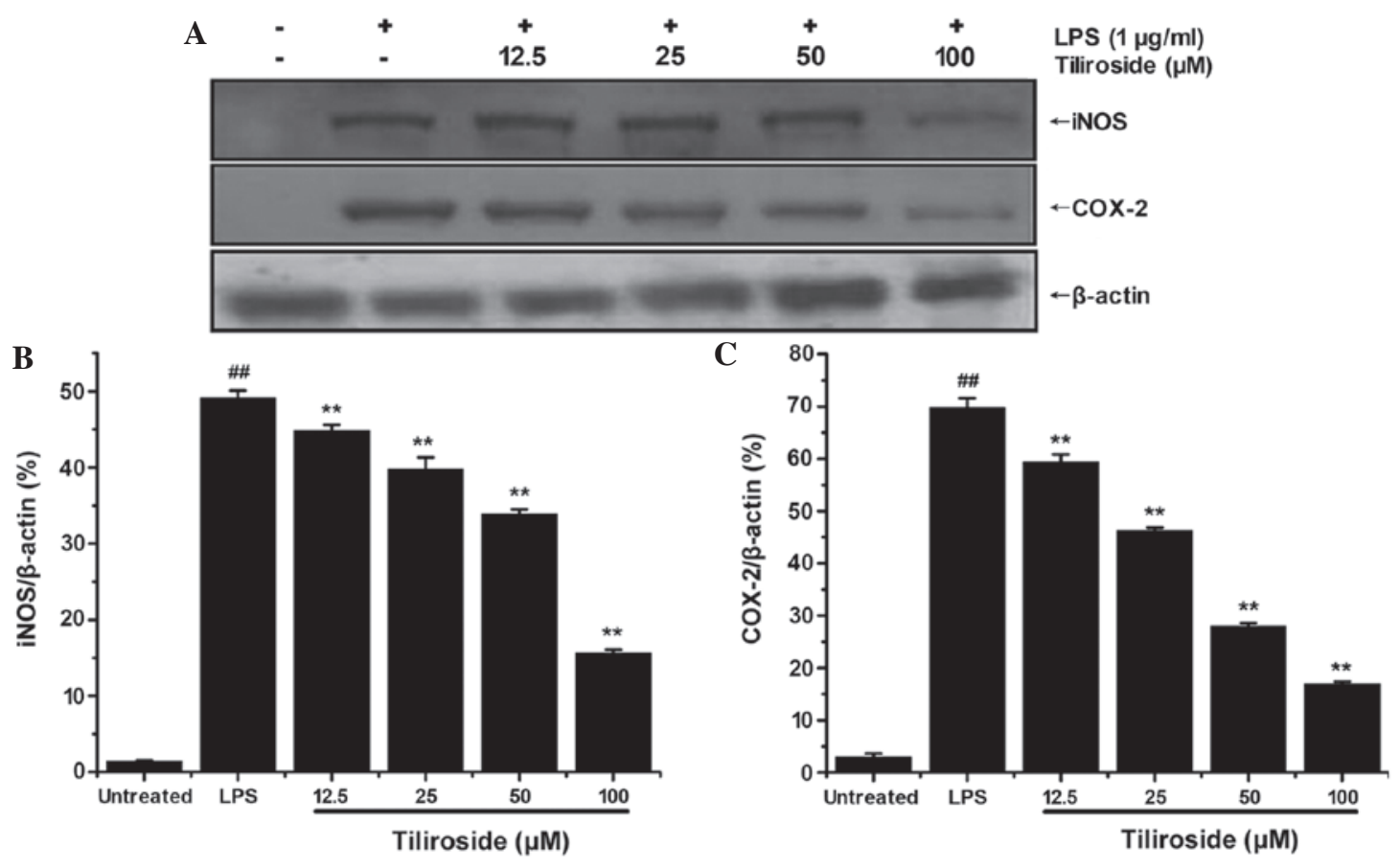

Figure 6. Effect of tiliroside on the expression of iNOS and COX-2 proteins. (A) RAW 264.7 cells were treated with LPS $1 \mu$ g/ml with or without tiliroside $(12.5,25,50$ and $100 \mu \mathrm{M})$ for $24 \mathrm{~h}$ and the expression levels of iNOS and COX-2 were assessed by western blot analysis. Detection of $\beta$-actin was performed to confirm the equal loading of proteins. Densitometric analysis of (B) iNOS and (C) COX-2 protein expression levels. Blots are representative of the \pm standard deviation of three separate experiments. Data were normalized with respect to $\beta$-actin levels. ${ }^{* *} \mathrm{P}<0.01 \mathrm{vs}$. LPS treatment group; ${ }^{\# \#} \mathrm{P}<0.01 \mathrm{vs}$. untreated group. LPS, lipopolysaccharide; iNOS, inducible nitric oxide synthase; COX-2, cyclooxygenase-2.

Fig. 7A-D, LPS significantly induced the phosphorylation of ERK1/2, JNK and p38 proteins $(\mathrm{P}<0.01)$. Treatment with tiliroside appeared to significantly reduce the phosphorylation of JNK and p38 proteins in a dose-dependent manner $(\mathrm{P}<0.01)$. By contrast, the phosphorylation of ERK 1/2 revealed no marked inhibition following treatment.

Effect of tiliroside on the degradation of $I \kappa B-\alpha$ protein. Transcription factor $N F-\kappa B$ has been confirmed to be important in the process of LPS-induced inflammation, including by elevation of iNOS and COX-2 expression levels (22). As the activation of $N F-\kappa B$ is typically initiated by the rapid degradation of $\mathrm{I} \kappa \mathrm{B}-\alpha$ protein, the present study investigated the expression levels of I $\kappa \mathrm{B}-\alpha$ by western blot analysis (Fig. 8A). The density of bands corresponding to I $\kappa \mathrm{B}-\alpha$ protein were normalized to $\beta$-actin and are displayed in Fig. 8B. As revealed in Fig. 8, LPS induced the rapid degradation of $\mathrm{I} \kappa \mathrm{B}-\alpha$ in RAW 264.7 cells compared with untreated cells $(\mathrm{P}<0.01)$. However, tiliroside demonstrated no marked effect on the degradation of I $\mathrm{B}-\alpha$. The results of the present study indicate that tiliroside may not affect the $\mathrm{NF}-\kappa \mathrm{B}$ signaling pathway. 
A
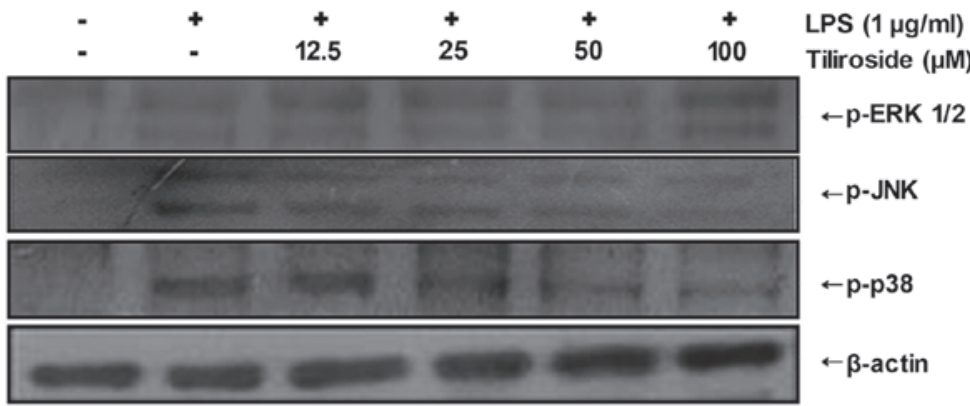

B

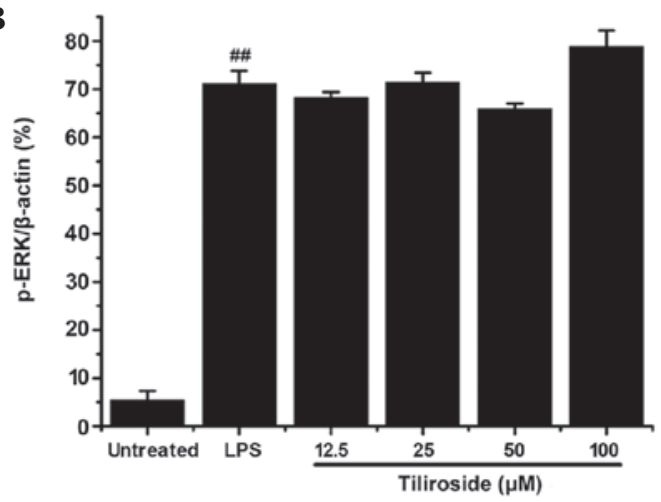

C

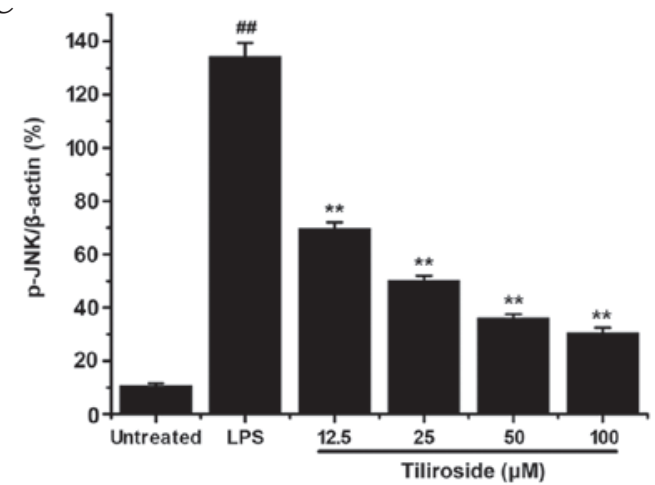

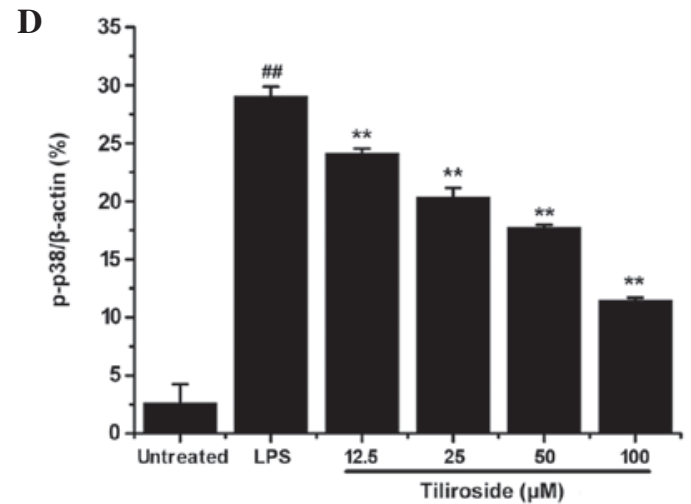

Figure 7. Effect of tiliroside on the phosphorylation of mitogen-activated protein kinase-ERK/JNK/p38 proteins. (A) RAW 264.7 cells were treated with LPS $1 \mu \mathrm{g} / \mathrm{ml}$ with or without tiliroside $(12.5,25,50$, and $100 \mu \mathrm{M})$ for $45 \mathrm{~min}$ and the expression of p-ERK1/2, p-JNK and p-p38 was assessed by western blot analysis. Detection of $\beta$-actin was conducted to confirm the equal loading of proteins. Densitometric analysis of p-ERK1/2 (B) p-JNK (C) and p-p38 (D) expression represent the mean \pm standard deviation of three separate experiments. Data were normalized with respect to $\beta$-actin levels. ${ }^{* *} \mathrm{P}<0.01 \mathrm{vs}$. LPS treatment group; ${ }^{\#} \mathrm{P}<0.01$ vs. untreated control group. LPS, lipopolysaccharide; p-, phosphorylated-; ERK 1/2, extracellular signal-regulated kinase 1/2; JNK, c-Jun N-terminal kinase.

A

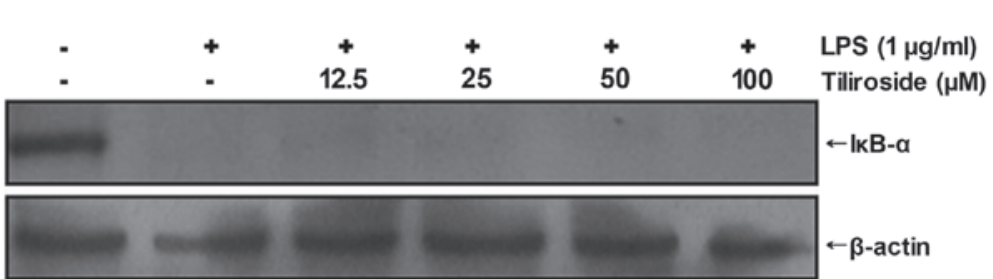

B

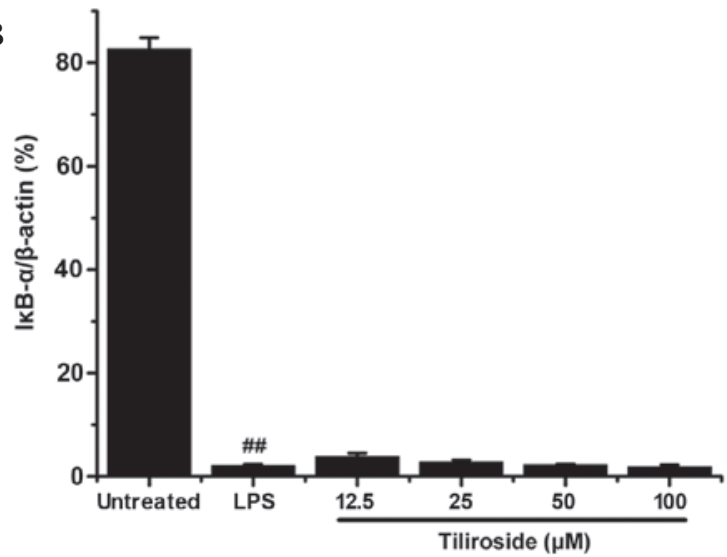

Figure 8. Effect of tiliroside on the degradation of IкB- $\alpha$ protein. (A) RAW 264.7 cells were treated with LPS $1 \mu \mathrm{g} / \mathrm{ml}$ with or without tiliroside (12.5, 25, 50 and $100 \mu \mathrm{M}$ ) for $15 \mathrm{~min}$ and the expression of IкB- $\alpha$ protein was assessed by western blot analysis. Detection of $\beta$-actin was conducted to confirm the equal loading of proteins. (B) Densitometric analysis of I $\kappa$ B- $\alpha$ protein. Expression represent the mean \pm standard deviation of three separate experiments. Data were normalized with respect to $\beta$-actin levels. ${ }^{\# \#} \mathrm{P}<0.01$ vs. untreated control group. LPS, lipopolysaccharide; IкB- $\alpha$, inhibitor of $\kappa B-\alpha$. 


\section{Discussion}

Previous references $(7,8)$ have reported that the methanol extract of AP inhibited the production of NO and PGE2 via the downregulation of iNOS and COX-2 expression in RAW 264.7 cells. The expression levels of proinflammatory cytokines IL-1 $\beta$ and IL- 6 were inhibited by methanol extract of AP, but no effect was observed in TNF- $\alpha$ production. Results in the present study demonstrated that a high dose of AP ethanol extract is able to significantly inhibit xylene-induced ear edema in mice and carrageenan-induced paw edema in rats, which further confirmed the anti-inflammatory effect of this plant. Tiliroside, the most abundant constituent in AP extract, is a natural glycosidic flavonoid and has been reported to possess a wide spectrum of biological activities. However, its molecular mechanism has yet to be elucidated; thus, the anti-inflammatory molecular mechanism of tiliroside was investigated in the present study. The results suggested that tiliroside is able to significantly suppress LPS-induced NO overproduction in RAW 264.7 cells in a dose-dependent manner. It also potently downregulated the protein expression levels of iNOS and COX-2. Further investigations indicated that tiliroside inhibits the phosphorylation of MAPK/JNK and MAPK/p38 proteins, but demonstrated no significant inhibition of the phosphorylation of MAPK/ERK or the degradation of I $\mathrm{B}-\alpha$.

In conclusion, the molecular mechanism regarding the anti-inflammatory effect of tiliroside may involve the downregulation of iNOS and COX-2 protein expression levels and is likely to mediate the inactivation of MAPK signaling pathway, however, the NF- $\kappa \mathrm{B}$ signaling pathway is not likely to have involvement in the process. This study presents the first direct evidence for the modulatory effect of tiliroside on the signal transduction pathway. The results suggest that tilliroside is the main active component of AP extract which exerts an anti-inflammatory effect through MAPK signaling pathway.

\section{Acknowledgements}

The present study was supported by the Project of National Natural Science Foundation of China (grant no. 81102781), the State Key Laboratory of Mycology (Institute of Microbiology, Chinese Academy of Sciences, Bejing, China), Taishan Scholar Project to Professor Fenghua Fu and the Undergraduate Scientific and Technological Innovation Project of Yantai University (grant no. 141801).

\section{References}

1. Park SH, Sim YB, Kang YJ, Lee JK, Lim SS and Suh HW: Effect of Agrimonia pilosa Ledeb extract on the antinociception and mechanisms in mouse. Korean J Physiol Pharmacol 16: 119-123, 2012.

2. Wang JP, Hsu MF and Teng CM: Antiplatelet effect of hsien-ho-t'sao (Agrimonia pilosa). Am J Chin Med 13: 109-118, 1985.
3. Wang JP, Hsu MF and Teng CM: Antihemostatic effect of hsien-ho-t'sao (Agrimonia pilosa). Am J Chin Med 12: 116-123, 1984.

4. Zhu L, Tan J, Wang B, He R, Liu Y and Zheng C: Antioxidant activities of aqueous extract from Agrimonia pilosa Ledeb and its fractions. Chem Biodivers 6: 1716-1726, 2009.

5. Shin WJ, Lee KH, Park MH and Seong BL: Broad-spectrum antiviral effect of Agrimonia pilosa extract on influenza viruses. Microbiol Immunol 54: 11-19, 2010.

6. Koshiura R, Miyamoto K, Ikeya Y and Taguchi H: Antitumor activity of methanol extract from roots of Agrimonia pilosa Ledeb. Jpn J Pharmacol 38: 9-16, 1985.

7. Kim JJ, Jiang J, Shim DW, Kwon SC, Kim TJ, Ye SK, Kim MK, Shin YK, Koppula S, Kang TB, et al: Anti-inflammatory and anti-allergic effects of Agrimonia pilosa Ledeb extract on murine cell lines and OVA-induced airway inflammation. J Ethnopharmacol 140: 213-221, 2012.

8. Jung CH, Kim JH, Park S, Kweon DH, Kim SH and Ko SG: Inhibitory effect of Agrimonia pilosa Ledeb on inflammation by suppression of iNOS and ROS production. Immunol Invest 39: 159-170, 2010

9. Yamaki M, Kashihara M, Ishiguro K and Takagi S: Antimicrobial principles of xian he cao (Agrimonia pilosa). Planta Med 55: $169-170,1989$.

10. Jung CH, Zhou S, Ding GX, Kim JH, Hong MH, Shin YC, Kim GJ and Ko SG: Antihyperglycemic activity of herb extracts on streptozotocin-induced diabetic rats. Biosci Biotechnol Biochem 70: 2556-2559, 2006.

11. Qin N, Li CB, Jin MN, Shi LH, Duan HQ and Niu WY: Synthesis and biological activity of novel tiliroside derivants. Eur J Med Chem 46: 5189-5195, 2011.

12. Zhu Y, Zhang Y, Liu Y, Chu H and Duan H: Synthesis and biological activity of trans-tiliroside derivatives as potent anti-diabetic agents. Molecules 15: 9174-9183, 2010.

13. Silva GC, Pereira AC, Rezende BA, da Silva JP, Cruz JS, de Souza MF, Gomes RA, Teles YC, Cortes SF and Lemos VS: Mechanism of the antihypertensive and vasorelaxant effects of the flavonoid tiliroside in resistance arteries. Planta Med 79: 1003-1008, 2013.

14. Qiao W, Zhao C, Qin N, Zhai HY and Duan HQ: Identification of trans-tiliroside as active principle with anti-hyperglycemic, anti-hyperlipidemic and antioxidant effects from Potentilla chinesis. J Ethnopharmacol 135: 515-521, 2011.

15. Sun DX, Lu JC, Fang ZZ, Zhang YY, Cao YF, Mao YX, Zhu LL, Yin J and Yang L: Reversible inhibition of three important human liver cytochrome p450 enzymes by tiliroside. Phytother Res 24: 1670-1675, 2010.

16. Sala A, Recio MC, Schinella GR, Máñez S, Giner RM, Cerdá-Nicolás M and Rosí JL: Assessment of the anti-inflammatory activity and free radical scavenger activity of tiliroside. Eur J Pharmacol 461: 53-61, 2003.

17. Denizot F and Lang R: Rapid colorimetric assay for cell growth and survival. Modifications to the tetrazolium dye procedure giving improved sensitivity and reliability. J Immunol Methods 89: 271-277, 1986.

18. Zhao F, Wang L and Liu K: In vitro anti-inflammatory effects of arctigenin, a lignan from Arctium lappa $L$., through inhibition on iNOS pathway. J Ethnopharmacol 122: 457-462, 2009.

19. Zhao F, Xu H, He EQ, Jiang YT and Liu K: Inhibitory effects of sesquiterpenes from Saussurea lappa on the overproduction of nitric oxide and TNF-alpha release in LPS-activated macrophages. J Asian Nat Prod Res 10: 1045-1053, 2008.

20. Zhao F, Gao Z, Jiao W, Chen L, Chen L and Yao X: In vitro anti-inflammatory effects of beta-carboline alkaloids, isolated from Picrasma quassioides, through inhibition of the iNOS pathway. Planta Med 78: 1906-1911, 2012.

21. Kaminska B: MAPK signalling pathways as molecular targets for anti-inflammatory therapy-from molecular mechanisms to therapeutic benefits. Biochim Biophys Acta 1754(1-2): 253-262, 2005.

22. Xie Q and Nathan C: The high-output nitric oxide pathway: Role and regulation. J Leukoc Biol 56: 576-582, 1994. 